\title{
The Role of Gender-Specific Factors in the Choice of Specialty Training in Obstetrics and Gynecology - Results from a Survey Among Medical Students in Germany
}

\section{Maximilian Riedel}

Klinikum rechts der Isar der Technischen Universitat Munchen https://orcid.org/0000-0002-9524-1514

\section{Andre Hennigs}

Department of Gynecology and Obstetrics, Heidelberg University Hospital

\section{Anna Maria Dobberkau}

Department of Gynecology and Obstetrics, Heidelberg University Hospital https://orcid.org/0000-00034280-2362

\section{Caroline Riedel}

Department of General Internal Medicine and Psychosomatics, Heidelberg University Hospital

\section{Till Johannes Bugaj}

Department of General Internal Medicine and Psychosomatics, Heidelberg University Hospital https://orcid.org/0000-0001-8287-2635

\section{Christoph Nikendei}

Department of General Internal Medicine and Psychosomatics, Heidelberg University Hospital

\section{Niklas Amann}

Department of Obstetrics and Gynecology, Ludwig Maximilians University (LMU)

\section{Anne Karge}

Klinikum rechts der Isar, Technical University Munich (TU)

\section{Gabriel Eisenkolb}

Klinikum rechts der Isar, Technical University Munich (TU)

\section{Maria Tensil}

Kirinius day care clinic, Munich

\section{Florian Recker}

Department of Obstetrics and Gynecology, Bonn University Hospital https://orcid.org/0000-0001-91354338

\section{Fabian Riedel ( $\sim$ fabian.riedel@gmail.com )}

Department of Gynecology and Obstetrics, Heidelberg University Hospital https://orcid.org/0000-00029693-2667 


\section{Research Article}

Keywords: gender, medical teaching, specialty training, obstetrics and gynecology, students

Posted Date: May 4th, 2021

DOl: https://doi.org/10.21203/rs.3.rs-428738/v1

License: (c) (i) This work is licensed under a Creative Commons Attribution 4.0 International License. Read Full License

Version of Record: A version of this preprint was published at Archives of Gynecology and Obstetrics on September 22nd, 2021. See the published version at https://doi.org/10.1007/s00404-021-06232-2. 


\section{The Role of Gender-Specific Factors in the Choice of Specialty \\ Training in Obstetrics and Gynecology - Results from a Survey}

among Medical Students in Germany

Maximilian Riedel ${ }^{1}$, André Hennigs², Anna Maria Dobberkau², Caroline Riedel ${ }^{3}$, Till Johannes Bugaj ${ }^{3}$, Christoph Nikendei ${ }^{3}$, Niklas Amann ${ }^{4}$, Anne Karge ${ }^{1}$, Gabriel Eisenkolb ${ }^{1}$, Maria Tensil ${ }^{5}$, Florian Recker ${ }^{6},{\text { Fabian } \text { Riedel }^{2}}^{2}$

\footnotetext{
${ }^{1}$ Department of Gynecology and Obstetrics, Klinikum rechts der Isar, Technical University Munich (TU), Munich, Germany

2 Department of Gynecology and Obstetrics, Heidelberg University Hospital, Heidelberg, Germany

3 Department of General Internal Medicine and Psychosomatics, Heidelberg University Hospital, Heidelberg, Germany

${ }^{4}$ Department of Obstetrics and Gynecology, Ludwig Maximilians University (LMU), Munich, Germany.

${ }^{5}$ Kirinius day care clinic, Munich, Germany

${ }^{6}$ Department of Obstetrics and Gynecology, Bonn University Hospital, Bonn, Germany
}

\section{Corresponding author:}

Dr. med. Fabian Riedel

Heidelberg University Hospital

Department of Gynecology and Obstetrics

Im Neuenheimer Feld 440

69120 Heidelberg, Germany

email: fabian.riedel@med.uni-heidelberg.de

phone: (+49) 6221-56-37366 


\section{$\underline{\text { Abstract }}$}

\section{Purpose}

The field of obstetrics and gynecology $(\mathrm{OB} / \mathrm{GYN})$ is facing growing competition for young professionals in Germany, with high interest rates among female graduates and a declining proportion of male students who choose residency training in the field. The aim of this study is to analyze general and gender-dependent factors that influence the decision for or against specialty training in $\mathrm{OB} / \mathrm{GYN}$ among medical students in Germany.

\section{Methods}

Between February and November 2019, $\mathrm{n}=346$ medical students in their $5^{\text {th }}$ and $6^{\text {th }}$ year of undergraduate training at Heidelberg University received a questionnaire with 44 items.

\section{Results}

$\mathrm{N}=286$ students (61.3 female; $38.7 \%$ male) participated in the study. $28 \%$ of the female students and $9 \%$ of the male students had considered $\mathrm{OB} / \mathrm{GYN}$ for their specialty training. The students reported different general and gender-specific influencing factors in their choice of a specialty. In comparison with their female colleagues, male students had heavily weighted factors related to their later careers and professional success, including competition among colleagues. Male students had gained little practical experience during compulsory internships (26.9\% for females vs. $8.8 \%$ for males) or had chosen their final-year elective in OB/GYN ( $15.9 \%$ for females vs. $5.5 \%$ for males). Female students had worried about the negative effects of their sex on their career (35.4\% for females vs. $5.9 \%$ for males).

\section{Conclusion}

OB/GYN must become more appealing and attractive to young female and male professionals alike. Better support for female clinicians in leadership positions should go hand in hand with the implementation of differentiated, (extra)curricular teaching approaches that take the different preferences of female and male students into account.

\section{Key words}

gender, medical teaching, specialty training, obstetrics and gynecology, students 


\section{$\underline{\text { Manuscript }}$}

\section{Introduction}

The development of improved gender diversity among medical students and professionals has considerably accelerated throughout the world in recent decades. In the USA, women comprised the majority of students (50.5\%) at American medical colleges in 2019 for the first time [1]. This trend has also been seen in the field of obstetrics and gynecology (OB/GYN) [2]. Similarly, in Germany, the gender distribution of medical students and physicians has shifted considerably. First, the share of female students in medicine has increased continuously, with women comprising two-thirds of all medical students today [3]. From a total of 98,763 medical students in Germany, 61,000 (62\%) were female in the 2018/19 winter semester [4]. Second, gender-dependent preferences have changed for some specialties yet remained stable for others during the same period of time. In $\mathrm{OB} / \mathrm{GYN}$, more than $80 \%$ of residents (Assistenzarzt/-ärztin) are female, while the majority of residents in other "classical" surgical specialties (e.g., general surgery, neuro-surgery, orthopedics) are male [5-7]. The share of male physicians who complete specialist training (Facharzt/-ärztin) in OB/GYN has shown a downward trend over the last three decades. In 2019, 93 (13.6\%) male vs. 598 (86.4\%) female physicians finished their specialist training in OB/GYN in Germany [7].

Women's preference for the specialty at the beginning of their careers stands in contrast to the distribution of leadership positions in $\mathrm{OB} / \mathrm{GYN}$ as female physicians reach these positions less frequently compared with their male colleagues. Women are underrepresented among senior physicians (Oberarzt/-ärztin) and clinical directors (Chefarzt/-ärztin) [8]. At the same time, the lack of physicians in outpatient- and inpatient medical care will continue to grow in the coming decades [9]. The total number of physicians who finish specialty training in OB/GYN has stagnated at around 700 per year [7], with an overproportionate number of female physicians working part-time [10]. Recruiting sufficient personnel for senior positions in OB/GYN has become an increasingly challenging task [11].

Understanding exactly what factors contribute to the final choice of a specialty remains an ongoing research question in the international literature. Few data dealing with genderdependent factors in the choice for or against a clinical career in $\mathrm{OB} / \mathrm{GYN}$ have thus far been collected in Germany. Apart from general career goals, such as motivation, practical experience, and maintaining a healthy work-life balance, the present study also focuses on 
gender-specific differences in students' perceptions of OB/GYN that may influence their choice of a specialty.

\section{Methods}

\section{Participation and criteria for inclusion}

Medical students in their $4^{\text {th }}$ or $5^{\text {th }}$ year of study before the beginning of their final year were invited to participate in the study. All participating students were enrolled at the Faculty of Medicine at Heidelberg University, Germany. The participants came from two groups. First, students who had participated in the four-week module "obstetrics and gynecology" within the compulsory curriculum of their medical studies were asked to participate $(n=176$ out of 286; 61.5\%). In addition, the department of obstetrics and gynecology at Heidelberg University Hospital offers a voluntary two-day extracurricular preparation course for the standardized written exam before the beginning of the final year. Further participants were recruited from this course $(\mathrm{n}=160$ out of $286 ; 38.5 \%)$. The study took place between February and November 2019. Participation was entirely voluntary, and non-participation had no consequences for a student's further course of study.

\section{Context of medical studies in Germany at the time of the study}

Medical studies in Germany are divided into three phases. The first two, pre-clinical years (Vorklinik) deal for the most part with basic science (anatomy, physiology, biology, chemistry, physics, etc.) in preparation for the following three years of comprehensive clinical teaching (Klinik) [12]. The clinical curriculum comprises in-depth teaching of all major and minor specialties in modules including lectures, seminars, and bedside teaching. The final year (Praktisches Jahr, PJ) concludes the medical studies [13]. During this final year, students work full-time in three blocks of 16-week training courses in internal medicine, surgery, and an elective specialty of their choice. Unlike the in the United States or the United Kingdom, there is no standardized or federal residency program for medicine in Germany. Specialty training begins after graduation at an accredited institution and usually takes 5-7 years. Students who aspire to complete residency apply directly with the head of the department or outpatient clinic. The final year of medical studies is therefore particularly important for medical students as it represents the transition toward their later occupation. After completing a nationwide standardized written exam before the beginning of the final year and a practical and verbal exam afterward, students earn their German Medical License (Approbation), and specialty 
training may begin. Both students and employers are aware of the impact of the final year on the application for a residency position. An application is generally more likely to be successful once a candidate has completed 16 weeks in an actual clinical setting face-to-face with potential employer(s), especially at competitive institutions. By making informed decisions about their elective and the institution for the final year of study, medical students can influence significant steps in their later careers.

\section{Informed consent}

An ethics approval was obtained in advance from the Ethics Committee of Heidelberg University (S-211/2019).

\section{Study design}

Students were asked about their motivations and reasons for or against their choice of a specialty both in general and for $\mathrm{OB} / \mathrm{GYN}$, in particular, via an anonymous questionnaire. The evaluation of gender-specific factors in choosing specialty training was particularly relevant. The questionnaire was distributed at the end of the aforementioned courses. It included a total of 44 items, 31 of which were rated on 5-point Likert scales ( $1=$ "strongly disagree (--)", $2=$ "disagree (-)", 3 = "neither agree nor disagree (-/+)", 4 = "agree" (+), 5 = "strongly agree" $(++))$, while the others were either dichotomous or classification questions.

\section{Statistical analysis}

The assessment was conducted via $\mathrm{R}^{\circledR}$ (version 4.0.3, $\mathrm{R}$ Core Team). Tables and figures were generated in Word ${ }^{\circledR}$ (version 2019, Microsoft) and GraphPad Prism ${ }^{\circledR}$ (version 9.0.1, GraphPad Software). $P$-values for statistical significance between female and male students were calculated using unpaired t-tests. $P$-values $<0.05$ were defined as statistically significant. Mean and relative values were calculated descriptively for each individual item. Possible genderdependent interactions were calculated using a generalized linear model (GLM) with desparsified lasso.

\section{Results}

General and gender-specific factors in the choice of a specialty

$\mathrm{N}=286$ students (female: 61.3; male: $38.7 \%$; participation rate: $82 \%$ ) completed the study. Interest in the subject matter, the subject-specific organs, or pathologies as well as a good 
working atmosphere were critical factors for the majority of both female and male students when choosing a specialty. By contrast, career factors - such as good career opportunities or potential earnings - were less important. Both the female and male students strived to maintain a decent work-life balance, but the women more-often sought to establish their own practice later (Tab. 1). In addition, a significant difference in the Likert scale between female and male students with regard to the relevance of career attributes was found. Attributes such as scientific work, competition among colleagues, and status/prestige were more appreciated by male students (Tab. 2). Female and male students considered the same experiences before and during their studies to be relevant to their personal choice of a specialty. The strongest factors in this context were positive experiences during internships, the final-year role models/mentors in the clinical setting, and the quality of the medical teaching, whereas experience with nursing abroad and influence from relatives or friends were less important (Tab. 3). Male students tended to consider conducting research and writing a thesis for a medical doctoral degree to be more influential on their decision (female: 19\%; male: 30\%; p-value: 0.05). Female students worried significantly more than male students about not finding mentors or role models of the same sex (mean: 1.4 vs. $2.1 ; p$-value: $<0.001$ ) and that their sex could be associated with disadvantages later in their clinical careers (mean: 1.4 vs. 2.8 ; $p$-value: $<0.001$ ).

\section{Gender-dependent perception and experience in obstetrics and gynecology}

Female and male participants had equally decided on a specialty (mean: 3.5 vs. 3.3; $p$-value: $0.15)$. Significantly more female (28\%) compared with male ( $8 \%)$ students had considered a future career in $\mathrm{OB} / \mathrm{GYN}$. In addition, internal medicine, surgery, and pediatrics were among the most-preferred specialties, independent of gender (Tab. 4). Both female and male students disagreed with the statement that women's healthcare should rest solely in the hands of female physicians (mean: 1.5 vs. 1.6; $p$-value: 0.35 ).

Compared with male students, their female counterparts had gained greater practical experience in $\mathrm{OB} / \mathrm{GYN}$ during their studies via nursing placements $(17.8 \%$ vs. $7.7 \% \mathrm{vs} ; p$-value: $<0.001)$, internships (26.9\% vs. $8.8 \%$; $p$-value: $<0.001)$, and (planned) electives in the final year of study $(15.9 \%$ vs $5.5 \%$; $p$-value: $<0.001)$. A lack of interest in the subject matter had more-often deterred male students from the specialty (15.9\% vs. 5.5\%; $p$-value: 0.0022$)$. By contrast, more female students had considered the heavy work- and shift load negatively (25\% vs. $10.3 \%$; $p$ value: 0.0023$)$. The intimacy of the medical topics (4.6\% vs. $6.9 \%$; $p$-value: 0.243$)$, the treatment of exclusively female patients (22.2\% vs. $25.9 \%$; $p$-value: 0.331$)$, and the high share 
of operative medicine in $\mathrm{OB} / \mathrm{GYN}(22.2 \%$ vs. $17.2 \%$; $p$-value: 0.418$)$ were found to be genderindependent (females vs. male) reasons for not pursuing a career in the field.

Next, the requirements of the fields of gynecology, (general) surgery, and urology were investigated in a comparative analysis. The students were asked to assess the share of the workload in the three areas of operative medicine, conservative oncology, and emergency medicine within the three fields. The gradual Likert scale revealed that the share of the workloads for the three areas within gynecology and urology were evaluated as being quite balanced, whereas (general) surgery was evaluated as having a clear predominance of operative medicine. No gender-dependent differences were observed except for assessments of the role of emergency medicine in gynecology ( $p$-value: 0.036) (Tab. 5).

Gender-dependent differences in the perception of and experience with the gynecological examination

Independent of gender, the majority of both female and male students considered the basic gynecological examination to be an important part of their clinical training (mean female: 3.8; mean male: 3.6 ; p-value: 0.18 ) and stressed that all practicing physicians must be qualified to perform the examination (mean female: 3.6; mean male: 3.7; p-value: 0.81). This finding contrasts with the practical experience of male students. Compared with their female counterparts, male students had less-frequently observed (30\% vs. $47 \%$ ) or carried out ( $8 \%$ vs. $24 \%$ ) an examination (under supervision). In total, $62 \%$ of male students versus $29 \%$ of female students had neither observed nor conducted a gynecological examination on their own during their studies ( $p$-value: $<0.001)$.

\section{Gender-dependent preferences in the choice of a sub-specialization}

After completing specialist medical training in $\mathrm{OB} / \mathrm{GYN}$, sub-specializations in pre-natal care \& special obstetrics, gynecological oncology, and gynecological endocrinology \& reproductive medicine are possible. In terms of the preferences for these sub-specializations among our students, a high preference level - especially among female students - was reported for prenatal care \& special obstetrics (female: $65 \%$; male: $46 \%$; p-value: 0.002 ). Male students, on the contrary, opted significantly more often for a sub-specialization in gynecological oncology (female: 18\%; male: 33\%; p-value: 0.005). Students showed balanced interest in gynecological endocrinology \& reproductive medicine, independent of their gender (female: $23 \%$; male: $23 \%$; p-value: 0.829) (Fig. 1). 


\section{Discussion}

Our data shed light on the different perceptions and experiences of female and male students in OB/GYN during their medical studies. These differences correspond to the later highly genderdependent choice of specialty training in OB/GYN. At the time of this study, most participants were ready to begin their final year of study and were therefore approaching the decision for or against a certain type of specialty training. Our data support the findings of previous studies as the students in our cohort (female: 58\%; male: 48\%) were highly sure of their choice of specialty training. About one-fourth (female: 24\%; male: 26\%) of students had not yet reached a decision.

Deciding on a certain type of specialty training is a very complex and dynamic process. Some students had made their decision very early during their studies, while others had made or planned to make the final decision just before, during, or even after their final year. Decisionmaking depends on both internal and external factors. Internal factors include gender, socioeconomic background, individual life- and family planning, expected future income, and interest or talent. External factors, by contrast, include experiences during internships or electives as well as influence by family members, friends, mentors, or role models in the clinical setting [14-16]. Studies indicate that compared with other specialties with a high operative workload, studies in $\mathrm{OB} / \mathrm{GYN}$ are particularly prone to deterring potential training candidates between the beginning of the clinical stage in the third year and the final year [17]. External factors - such as positive experiences with internships, electives, or medical classes - have been found to play a decisive role in final career decisions, and these practical experiences were particularly relevant for the students in our study. In general, positive experiences can be seen to be an important motivational factor for students when choosing to engage in a specialty in greater depth and eventually selecting it for later training [18]. As already demonstrated, extracurricular preparation courses for the state exam have a potentially positive impact on the decision of specialty training in $\mathrm{OB} / \mathrm{GYN}[19,20]$.

Gender-dependent issues and challenges exist in both medical studies and specialty training. We observed that female students, in particular, expect disadvantages in their later career due to their sex. This finding is consistent with reports from international studies indicating that female students experience more gender discrimination and less support from mentors and that they are less confident in their academic achievements in OB/GYN [21]. In general, this problem applies more frequently to women; however, in one American study, men and women alike reported the highest degree of discrimination in (general) surgery and OB/GYN [22]. The 
authors speculate that a variety of reasons - such as patient characteristics, daily work, interaction with nursing staff, or the sex of supervisors or colleagues - might account for this finding [22]. Interestingly, these two specialties are also among those with the highest levels of gender discrepancy among physicians in Germany [7].

Several international studies have investigated the role of gender on the choice of specialty training. The heterogeneous results indicate that this decision also depends on cultural and socio-economics factors. While Swedish medical students, for example, have genderindependent preferences [23], female students in Saudi Arabia more-frequently pursue a career in surgery, ophthalmology, or pediatrics [24]. In general, the global trend is for female students to favor general medicine, pediatrics, or OB/GYN [22]. These findings are consistent with the data from our study. Moreover, in our study, male students showed little interest in OB/GYN. This finding corresponds well with those of the international literature, although the high reported preference levels of male students for other specialties - usually those with a demanding surgical workload, such as (general) surgery [25], orthopedics [26], neurosurgery [27], or urology [28] - were not found in our analysis.

Factors that explicitly distinguish OB/GYN from other specialties - such as the exclusively female patients or the intimate nature of the female medical problems - did not play a distinguishing role in the choice of female vs. male students for specialization in the field. Comparing OB/GYN with (general) surgery, the operative workload was less-significantly considered, independent of gender. Interestingly, the opportunity to work surgically was reported by one American study as being a crucial factor in male students' interest in OB/GYN [29]. We speculate that this could be one reason why more male students who want to pursue primarily surgical training might be put off by $\mathrm{OB} / \mathrm{GYN}$ due to the broad spectrum and diverse sub-specializations of the field [30].

Studies indicate that male students have less practical experience in OB/GYN compared with female students [31]. Our data reveal that $78 \%$ of male students had no practical experience beyond the compulsory albeit limited bedside teaching in the OB/GYN course. One American publication reported that male students had been dissatisfied with the practical experience in $\mathrm{OB} / \mathrm{GYN}$ and suggested that this was due to their gender [32]. The male students in the aforementioned study had had fewer opportunities to actually learn and practice the gynecological examination $[32,33]$, which is consistent with the finding of our study as $62 \%$ of our male students had neither observed nor conducted an examination on their own. However, this finding contrasts with the gender-independent majority view in our study namely that all physicians should be competent in gynecological examinations and that this 
skill should be part of the compulsory curriculum for medical teaching. The literature reveals that the discrepancy between these practical experiences is not due to patients' primary preference for female examiners because satisfaction with the examination does not correlate with the sex of the examiner [34, 35]. Empathy and good communication skills are crucial in this context [36]. By contrast, evidence suggests that supervisors are in fact the strongest obstacle to learning the gynecological examination as they can actively prohibit male students from participating or passively exclude them [37].

\section{Limitations}

To the best of our knowledge, this is the first survey among German medical students to provide an in-depth analysis of the gender-specific elements that influence the choice for or against specialty training in $\mathrm{OB} / \mathrm{GYN}$. Limitations in our results stem from the monocentric approach at Heidelberg University and the use of a questionnaire to collect data. Further research approaches in the future may use additional qualitative methods (for example, structured interviews). Our cohort of students formed a rather homogeneous group as all of them were in an advanced phase of their studies, and we could therefore not investigate dynamic processes with regard to gender-dependent preferences over the entire course of study. However, it was advantageous for our study to focus on students who needed to choose their specialty training in the near future as these students may have already deliberately given thought to the choice. Students filled out the questionnaire after either the OB/GYN curricular module or the stateexam-preparation course in $\mathrm{OB} / \mathrm{GYN}$. Therefore, a response bias from the very recent theoretical and practical experience in the specialty - either positive or negative - cannot be excluded. Although the questionnaires were answered anonymously and individually, we could not exclude an effect caused by social desirability, for example, for items dealing with gender equality or the work-life balance.

\section{Conclusion}

Competition among young professionals has been intensifying in Germany in recent decades. This competition is particularly relevant in $\mathrm{OB} / \mathrm{GYN}$ as the field now faces two simultaneous issues: First, female physicians are underrepresented in leading clinical and scientific positions, and second, specialty training in $\mathrm{OB} / \mathrm{GYN}$ has become increasingly less appealing for male students in the last three decades. It is therefore now necessary to take specific actions to improve the recruitment of male and female physicians alike. We consider the following steps 
to be important: I) well-directed and active promotion of women in their clinical and research career, II) structural changes in the clinical setting that support the compatibility of career and family, III) extracurricular activities and courses for students that stress unique subspecializations and gender-specific preferences, and IV) an improved and more-diversified public portrayal of the specialty with regard to the high and challenging operative workload and its diverse sub-specializations. New approaches in this regard are illustrated in the new information and promotion portal for medical students (Gyn werden) hosted by the Young Forum of the German Society for Obstetrics and Gynecology (Junges Forum in der DGGG) [38]. This website aims to motivate female and male students alike to choose specialty training in $\mathrm{OB} / \mathrm{GYN}$ in Germany. We also believe that the conclusions reached in this study should also applicable for other healthcare systems around the world.

\section{Declarations}

\section{Funding:}

Not applicable.

\section{Potential conflict of interest}

Niklas Amann and Florian Recker are members of the Young Forum of the German Society for Obstetrics and Gynecology (Junges Forum in der DGGG). All other authors declare no potential conflict of interest.

Availability of data and material:

All (raw) data and material are available upon reasonable request.

\section{Code availability:}

Not applicable.

\section{Authors' contributions:}

Maximilian Riedel, Fabian Riedel, and André Hennigs planned and designed the study. Anna Maria Dobberkau, Maximilian Riedel, and Maria Tensil performed the statistical analysis. Maximilian Riedel, Fabian Riedel, and Anna Maria Dobberkau analyzed and interpreted the data. Fabian Riedel, André Hennigs, and Caroline Riedel collected the data. Maximilian Riedel and Fabian Riedel wrote the manuscript. Till Johannes Bugaj, Niklas Amann, Anne Karge, 
Florian Recker, Christoph Nikendei, and Gabriel Eisenkolb provided conceptional assistance. All co-authors examined the manuscript, made corrections, and approved it for publication.

\section{Ethics approval:}

An ethics approval was obtained in advance from the ethics committee of Heidelberg

University (S-211/2019).

\section{Consent to participate:}

Participation in the study was entirely voluntary. Written consent had been obtained from all participants before the study.

\section{Consent for publication:}

All authors consent to the publication of this manuscript.

\section{Tables}

\section{Table 1}

Students' responses (in absolute and relative numbers) to the following statement: "What factors positively influenced your choice of a specialty?"

\section{Table 2}

Mean Likert scale (" 1 " = completely disagree; " 5 " = completely agree) depicting factors that positively influence the choice of a specialty.

\section{Table 3}

Students' responses (in absolute and relative numbers) to the following statement: "What experiences positively influenced your choice of specialty training?"

\section{Table 4}

Students' preference (in absolute and relative numbers) for specialty training.

\section{Table 5}

Mean Likert scale ("1" = completely disagree; "5" = completely agree) depicting students' differential perception of gynecology, urology, and surgery. 


\section{Figures}

\section{Figure 1}

Bar diagram depicting female $(n=176)$ and male $(n=110)$ preferences $($ in $\%)$ for one of the sub-specializations in OB/GYN (pre-natal care \& special obstetrics, gynecological oncology, and gynecological endocrinology \& reproductive medicine) in different gray scales.

\section{References}

[1] 2019 Fall Applicant, Matriculant, and Enrollment Data Tables. 2019. Im Internet: https://www.aamc.org/system/files/2019-

12/2019\%20AAMC\%20Fall\%20Applicant\%2C\%20Matriculant\%2C\%20and $\% 20$ Enrollment $\% 20$ Data\%20Tables_0.pdf

[2] Wooding DJ, Das P, Tiwana S, et al. Race, ethnicity, and gender in academic obstetrics and gynecology: 12-year trends. American Journal of Obstetrics \& Gynecology MFM 2020; 2: 100178. doi:10.1016/j.ajogmf.2020.100178

[3] Hancke K, Toth B, Igl W, et al. Career and Family - Are They Compatible?: Results of a Survey of Male and Female Gynaecologists in Germany. Geburtshilfe Frauenheilkd 2012; 72: 403-407. doi:10.1055/s-0031-1298393

[4] statista - Geschlechterverteilung Medizin Studierende in Deutschland. 2020. Im Internet: https:/de.statista.com/statistik/daten/studie/200758/umfrage/entwicklung-deranzahl-der-medizinstudenten/

[5] Riepen T, Möbus V, Kullmer U, et al. Male and Female Physicians in Hospital Gynaecology Departments - Analysis of the Impact of "Feminisation" from the Viewpoint of Medical Directors. Geburtshilfe Frauenheilkd 2013; 73: 53-58. doi:10.1055/s-0032-1328185

[6] Protschka. Frauenanteil Chirurgie: Frauen planen in Etappen. Dtsch Arztebl International 2014: 1246

[7] ВÄK 2019 - Anerkennung von Facharztbezeichnungen. . Im Internet: https://www.bundesaerztekammer.de/fileadmin/user_upload/downloads/pdfOrdner/Statistik2019/Stat19Tab09.pdf; Stand: 08.11.2020

[8] Beerheide B Rebecca. Ärztinnenstatistik: Ärztinnen gelangen selten in Spitzenpositionen. Dtsch Arztebl International 2015: 452

[9] Kaduszkiewicz H, Teichert U, van den Bussche H. Ärztemangel in der hausärztlichen Versorgung auf dem Lande und im Öffentlichen Gesundheitsdienst: Eine kritische Analyse der Evidenz bezüglich der Rolle von Aus- und Weiterbildung. Bundesgesundheitsbl 2018; 61: 187-194. doi:10.1007/s00103-017-2671-1

[10] Schott S, Lermann J, Eismann S, et al. Part-time employment of gynecologists and obstetricians: a sub-group analysis of a Germany-wide survey of residents. Arch Gynecol Obstet 2017; 295: 133-140. doi:10.1007/s00404-016-4220-9

[11] Mallmann P. Das Nachwuchsproblem in unserem Fach. Frauenarzt 2017: 88

[12] Nikendei C, Weyrich P, Jünger J, et al. Medical education in Germany. Medical Teacher 2009; 31: 591-600. doi:10.1080/01421590902833010

[13] Nikendei C, Krautter M, Celebi N, et al. Final Year Medical Education in Germany. Zeitschrift für Evidenz, Fortbildung und Qualität im Gesundheitswesen 2012; 106: 75-84. doi:10.1016/j.zefq.2012.01.002

[14] Hammoud MM, Stansfield RB, Katz NT, et al. The effect of the obstetrics and 
gynecology clerkship on students' interest in a career in obstetrics and gynecology. Am J Obstet Gynecol 2006; 195: 1422-1426. doi:10.1016/j.ajog.2006.07.044

[15] Kasch R, Baum P, Dokter M, et al. Nursing Practicum in Gynaecology and Obstetrics - Early Influence Possibilities for a Specialty. Geburtshilfe Frauenheilkd 2015; 75: 12701275. doi:10.1055/s-0035-1558053

[16] Kwon OY, Park SY. Specialty choice preference of medical students according to personality traits by Five-Factor Model. Korean J Med Educ 2016; 28: 95-102.

doi:10.3946/kjme.2016.14

[17] Birck S, Gedrose B, Robra B-P, et al. Stabilität der beruflichen Endziele im Verlauf der fachärztlichen Weiterbildung. Dtsch med Wochenschr 2014; 139: 2173-2177. doi:10.1055/s-0034-1387274

[18] Mihalynuk T, Leung G, Fraser J, et al. Free choice and career choice: Clerkship electives in medical education. Med Educ 2006; 40: 1065-1071. doi:10.1111/j.13652929.2006.02614.x

[19] Riedel F, Riedel M, Freis A, et al. Exam preparatory course for the 2nd part of the German medical examination in obstetrics and gynecology - a potential tool for the recruitment of new residents during the occupational decision process before the practical year? BMC Med Educ 2019; 19: 24. doi:10.1186/s12909-019-1457-6

[20] Riedel F, Fremd C, Tabatabai P, et al. Exam preparation course in obstetrics and gynecology for the German Medical State Examination: proof of concept and implications for the recruitment of future residents. Arch Gynecol Obstet 2016; 294: 1235-1241. doi:10.1007/s00404-016-4168-9

[21] Berlingo L, Girault A, Azria E, et al. Women and academic careers in obstetrics and gynaecology: aspirations and obstacles among postgraduate trainees - a mixed-methods study. BJOG 2019; 126: 770-777. doi:10.1111/1471-0528.15574

[22] Nora LM, McLaughlin MA, Fosson SE, et al. Gender discrimination and sexual harassment in medical education: perspectives gained by a 14-school study. Acad Med 2002; 77: 1226-1234. doi:10.1097/00001888-200212000-00018

[23] Diderichsen S, Johansson EE, Verdonk P, et al. Few gender differences in specialty preferences and motivational factors: a cross-sectional Swedish study on last-year medical students. BMC Med Educ 2013; 13: 39. doi:10.1186/1472-6920-13-39

[24] Mehmood SI, Kumar A, Al-Binali A, et al. Specialty preferences: trends and perceptions among Saudi undergraduate medical students. Med Teach 2012; 34 Suppl 1: S5160. doi:10.3109/0142159X.2012.656753

[25] Baschera D, O’Donnell Taylor E, Masilonyane-Jones T, et al. Are Medical Students Who Want to Become Surgeons Different? An International Cross-Sectional Study. World J Surg 2015; 39: 2908-2918. doi:10.1007/s00268-015-3195-1

[26] Schroeder JE, Zisk-Rony RY, Liebergall M, et al. Medical students' and interns' interest in orthopedic surgery: the gender factor. J Surg Educ 2014; 71: 198-204. doi:10.1016/j.jsurg.2013.08.005

[27] Dixon A, Silva NA, Sotayo A, et al. Female Medical Student Retention in Neurosurgery: A Multifaceted Approach. World Neurosurg 2019; 122: 245-251. doi:10.1016/j.wneu.2018.10.166

[28] Jayakumar N, Ahmed K, Challacombe B. Factors affecting UK medical students' decision to train in urology: a national survey. Minerva Urol Nefrol 2016; 68: 409-416 [29] Schnuth RL, Vasilenko P, Mavis B, et al. What influences medical students to pursue careers in obstetrics and gynecology? American Journal of Obstetrics and Gynecology 2003; 189: 639-643. doi:10.1067/S0002-9378(03)00886-X

[30] Schmidt LE, Cooper CA, Guo WA. Factors influencing US medical students' decision to pursue surgery. J Surg Res 2016; 203: 64-74. doi:10.1016/j.jss.2016.03.054

[31] Chang JC, Odrobina MR, McIntyre-Seltman K. The Effect of Student Gender on the 
Obstetrics and Gynecology Clerkship Experience. Journal of Women's Health 2010; 19: 8792. doi:10.1089/jwh.2009.1357

[32] Wallbridge T, Holden A, Picton A, et al. Does medical students' gender affect their clinical learning of gynaecological examination? A retrospective cohort study. Postgrad Med J 2018; 94: 325-329. doi:10.1136/postgradmedj-2017-135390

[33] Zahid AZM, Ismail Z, Abdullah B, et al. Gender bias in training of medical students in obstetrics and gynaecology: a myth or reality? Eur J Obstet Gynecol Reprod Biol 2015; 186:

17-21. doi:10.1016/j.ejogrb.2014.12.018

[34] Childs AJ, Friedman WH, Schwartz MP, et al. Female Patients' Sex Preferences in Selection of Gynecologists and Surgeons: Southern Medical Journal 2005; 98: 405-408. doi:10.1097/01.SMJ.0000129925.70634.53

[35] Johnson AM, Schnatz PF, Kelsey AM, et al. Do women prefer care from female or male obstetrician-gynecologists? A study of patient gender preference. J Am Osteopath Assoc 2005; 105: 369-379

[36] Plunkett BA, Kohli P, Milad MP. The importance of physician gender in the selection of an obstetrician or a gynecologist. Am J Obstet Gynecol 2002; 186: 926-928.

doi:10.1067/mob.2002.123401

[37] van den Einden LCG, te Kolste MGJ, Lagro-Janssen ALM, et al. Medical students' perceptions of the physician's role in not allowing them to perform gynecological examinations. Acad Med 2014; 89: 77-83. doi:10.1097/ACM.0000000000000055 [38] "Gyn-werden" des Jungen Formus der DGGG. 2020. Im Internet: https://www.gynwerden.de 


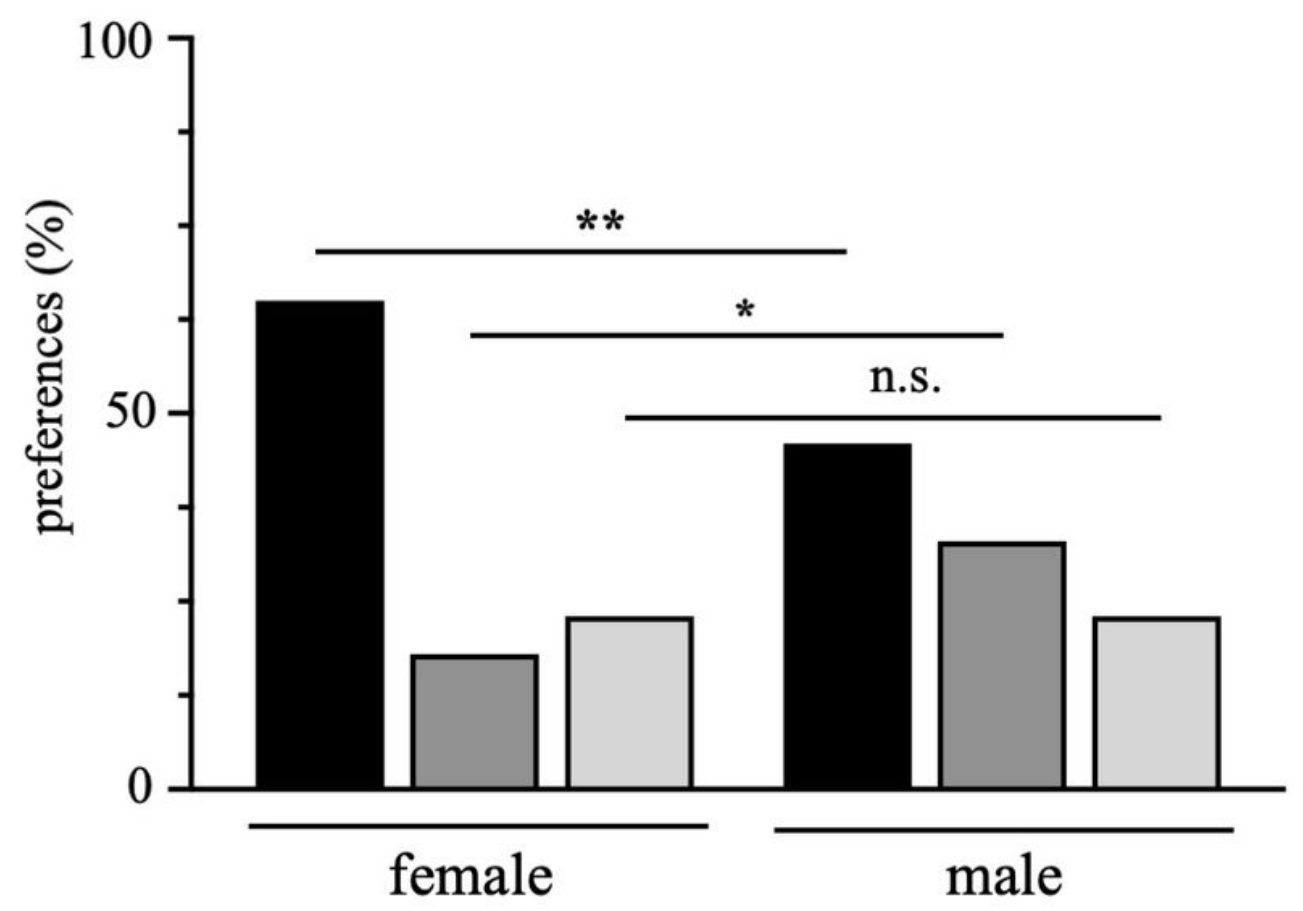

Figure 1

Bar diagram depicting female $(n=176)$ and male $(n=110)$ preferences (in \%) for one of the subspecializations in OB/GYN (pre-natal care \& special obstetrics, gynecological oncology, and gynecological endocrinology \& reproductive medicine) in different gray scales.

\section{Supplementary Files}

This is a list of supplementary files associated with this preprint. Click to download.

- tablesMRI.pdf 